\title{
Article
}

\section{What makes health visiting successful- or not? 2. The service journey}

Cowley, Sarah, Malone, Mary, Whittaker, Karen, Donetto, Sara, Grigulis, Astrida and Maben, Jill

Available at http://clok.uclan.ac.uk/23950/

Cowley, Sarah, Malone, Mary, Whittaker, Karen ORCID: 0000-0002-3493-9396, Donetto, Sara, Grigulis, Astrida and Maben, Jill (2018) What makes health visiting successful-or not? 2. The service journey. Journal of Health Visiting, 6 (8). pp. 404-412. ISSN 2050-8719

It is advisable to refer to the publisher's version if you intend to cite from the work. 10.12968/johv.2018.6.8.404

For more information about UCLan's research in this area go to http://www.uclan.ac.uk/researchgroups/ and search for <name of research Group>.

For information about Research generally at UCLan please go to http://www.uclan.ac.uk/research/

All outputs in CLoK are protected by Intellectual Property Rights law, including Copyright law. Copyright, IPR and Moral Rights for the works on this site are retained by the individual authors and/or other copyright owners. Terms and conditions for use of this material are defined in the policies page.

\section{CLoK}

Central Lancashire online Knowledge www.clok.uclan.ac.uk

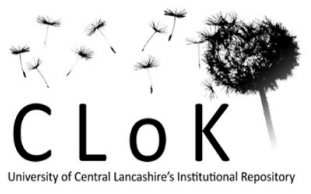




\title{
Author Accepted Manuscript
}

Published text available as:

Cowley, Sarah, Malone, Mary, Whittaker, Karen (D), Donetto, Sara, Grigulis, Astrida and Maben, Jill (2018) What makes health visiting successful-or not? 2. The service journey. Journal of Health Visiting, 6 (8). pp. 404-412. ISSN 2050-8719

Official URL: https://doi.org/10.12968/johv.2018.6.8.404

What makes health visiting successful - or not? 2. Principles of the service journey

\section{Authors}

Sarah Cowley ${ }^{1}$, Mary Malone ${ }^{2}$, Karen Whittaker*3, Sara Donetto ${ }^{4}$, Astrida Grigulis ${ }^{5}$, Jill Maben $^{6}$

Key words: Health Visitors; Maternal Child Health Services; Health Promotion; Service Users; Relationships; Skill mix

\begin{abstract}
This is the second of two papers reporting evidence from a programme of research that focused on how health visiting works, including service user and workforce perspectives. Evidence and professional expertise indicate that a set of essential features enable health visitors to achieve the desired impact of improving child public health. These include organising services in a way that enables positive parent/health visitor relationships, continuity and co-ordination and the flexibility to use professional knowledge and autonomy in practice. Where service specifications give careful attention to this evidence, it is more likely that health visitors will be able to deliver a successful child health programme for the early years.
\end{abstract}

Sarah Cowley ${ }^{1}$, Emeritus Professor Dame Sarah Cowley, King's College London Mary Malone ${ }^{2}$, Head of Department of Adult Nursing, King's College London 
Karen Whittaker ${ }^{3}$, Reader Child and Family Health, University of Central Lancashire Sara Donetto ${ }^{4}$, Lecturer, King's College London

Astrida Grigulis ${ }^{5}$, King's College London

Jill Maben ${ }^{6}$ Professor of Health Services Research and Nursing, University of Surrey.

*Correspondence: Dr Karen Whittaker; kwhittaker1@uclan.ac.uk Tel: +44 (0)1772 893786 Twitter @kwhittaker1

Key Points:

- Health visiting services directed at improved parent and child wellbeing have the potential to secure important public health goals, but the way provision is organised can help or hinder the extent of their success.

- Relationships are central to the provision. Health visiting services are unsolicited, so starting the journey well through relationship building is imperative to what may follow.

- Service models need to enable continuity in care, and as part of that, collaboration with allied services.

- Parents find team and skill mix approaches more acceptable where they are well co-ordinated, but evidence about their impact on outcomes is lacking.

- Highly developed skills, flexibility and autonomy in practice are necessary to enable health visitors to tailor provision to need and maintain client sensitive care, particularly where there are complex needs or tensions between public health expectations, official requirements and parental beliefs and context. 


\section{Background}

The English Health Visitor Implementation Plan (HVIP) (Department of Health 2011) spearheaded a four-year programme of development and increase in the size of the workforce in England. The programme introduced a new service model which emphasised the principles of universality and a way of achieving improved equity in health service delivery for families with young children. Since it ended, national health policy changes resulted in shifting the responsibility for commissioning universal child health services, from the National Health Service to local authority public health and well-being boards. This also coincided with significant funding constraints and a sharp reduction in the public health budget. Therefore, some commissioners have reduced funding for health visiting services, sometimes identifying a particular, and limited, range of services for health visiting provision, or by substituting alternative staff to carry out key contacts. Curtailing the service in this way carries the risk of eroding the features that are necessary for health visiting to be successful in its aims and purpose. This paper is the second of two that aim to describe the essential features of a successful health visiting service, drawing on a programme of research commissioned as part of the HVIP (Department of Health 2011). As in the first paper (under review), we note that research information about what contributes to the success of health visiting services, taken together with professional and organizational expertise, can show how likely it is that the overall provision will succeed in its particular public health aims. We describe this as being 'successful,' rather than using the term 'effective,' which is closely implicated with specific forms of research.

Health visitors are qualified health professionals who provide a public health service focused primarily upon pre-school children and their families and, where commissioned, will reach out to other vulnerable groups such as asylum seekers or homeless populations. Health visitors draw on a wide range of evidence for the services they provide. In England, they lead delivery of the Healthy Child Programme (HCP) (Department of Health 2009), which is underpinned by evidence of what works to 
promote and improve the health and wellbeing of children aged up to five years old (Barlow et al 2008, Axford et al 2015). There is a swathe of NICE guidance documents that summarise key evidence for health improvement in this age as well, which were summarised in the first paper (under review). Both these sources of evidence will be discussed further below.

There are also trials of specific aspects of health visiting. As examples, Morrell et al.'s (2009) cluster trial demonstrated that health visitors with additional training can effectively identify and treat post-natal depression, even preventing it in some cases (Brugha et al 2011). Health visitors trained in the Family Partnership Model (FPM), a UKdeveloped relationship-based approach to working with parents (Davis and Day 2010), were evaluated using antenatal and post-natal promotional guides (Day et al 2014). This partnership approach led to improvements in mother-child interactions and better identification of health needs (Davis et al 2005, Puura et al 2005). A randomized controlled trial (RCT) of monthly home visiting by health visitors demonstrated more relaxed mothering and confidence in services, leading to their better use (Wiggins et al 2005). Such studies show that health visitors can make a difference, if they have appropriate skills and capacity to identify which families need additional support, then to deliver appropriate help or refer to other services as needed.

The first of our two papers explained that health visiting services need to be based upon a principle of universality (under review). This ensures that all families receive a basic minimum provision and offers a mechanism through which services can be tailored and targeted according to need - described by Marmot (2010) as 'proportionate universalism' - which is essential for tackling inequalities. The 4-5-6 model of service delivery identified through the Health Visitor Implementation Plan specifies four levels (community, universal, universal plus and universal partnership plus), and mandates five health reviews, which are intended to lead to six 'high impact' outcomes (Public Health England 2016). Different service models pertain to Scotland (Scottish Government, 
2015), Wales (Welsh Government, 2016) and Northern Ireland (Department of Health Social Services and Public Safety, 2010), which specify more frequent core contacts, to be delivered by qualified health visitors rather than a mixed team.

\section{The programme of research}

This paper draws upon a programme of health visiting research that encompassed three studies, summarised in Box 1. Each of the three studies incorporated recommendations for service, education, policy and research, based upon the findings. An analysis of these recommendations revealed some themes that recurred across all three studies, demonstrating key elements that help to make health visiting more or less successful in enabling health gains for pregnant women, pre-school children and their families. These themes form the basis for recommended principles that should underpin the organisation of health visiting services.

Place Box 1 near here

The first of these organisational principles concerned the importance of universality as the fundamental basis for all health visiting services, which was explained in the earlier paper (under review). This second paper will explain three further principles that should underpin the organisation of health visiting services. These are:

1. Relationships are at the core of all health visiting provision.

2. Continuity and co-ordination are essential elements of team working.

3. Professional autonomy is a necessary requirement, which enables health visitors to provide a flexible service, tailored to individual need.

For this paper, we also examined evidence of what works to promote child and family health from relevant NICE guidelines and the rapid review to update evidence for the Healthy Child Programme (Axford et al 2015). Our research findings were consistent with recurring messages from these sources, as summarised in Box 2.

Place Box 2 near here 
The paper will explain how these recommended principles and research-based messages underpin the organisation of evidence-based health visiting provision. The extent to which they are implemented will help or hinder the delivery of a successful health visiting service.

\section{The service journey}

Some important, recurring concepts identified in the literature review were analysed and used to formulate a tentative explanation for how the health visiting service promotes and enables family health, which we named 'the service journey.' This service journey begins for the new or expectant parent when the health visitor seeks them out, rather than responding to a referral or request, as happens with most other health and social care provision. The process of developing a trusting relationship between parent(s) and health visitor starts at this first contact, then varies in intensity according to need and the age of the infant. This relationship is the main vehicle driving the service journey, with parents concurrently developing their own confidence and knowledge of parenting and their developing child, as they learn to make best use the services.

The health visiting service is both proactive and, in most instances, unfamiliar to new parents, particularly for their first baby. However, the service can only be effective if it is delivered to those who need it, in a way that is proportionate and appropriate to their needs (see Cowley et al 2015, Cowley et al, under review). As a result, health visitor activities need to operate in a way that enables parents to understand and avail themselves of the provision.

\section{Relationships}

Relationship formation is at the core of effective health visiting and helps to facilitate health improvement and resilience. There is wide agreement across the literature 
about the importance of relationships. For example, Axford et al (2015) indicate that developing and sustaining relationships is essential to health promotion for the most vulnerable children, who often live in families with a history of non-engagement with health and social care. Relationship formation is one of three core health visiting practices revealed in our literature review, along with home visiting and needs assessment. All three practices appeared interdependent, with each study about one also describing the other two, to give effect to the practice of primary interest. To illustrate, Bryans' (2005) study about home visiting described how this practice helped health visitors to achieve needs assessments and develop a trusting relationship with parents. Similarly, Appleton and Cowley $(1998 \mathrm{a}, \mathrm{b})$ described the centrality of a relationship and home visits in assessing health needs. The programme of research offered many examples of health visitors using finely honed skills and sensitivity to deliver clearly purposeful and effective practice, meeting needs as they arise (Cowley et al, 2013, 2015, Donetto et al, 2013, Donetto and Maben 2015). Where the skills, time or continuity were missing, trusting relationships could not be developed and services were experienced as inadequate (Bidmead 2013).

Ideally, each contact forms part of a framework through which the whole service is delivered, with the parent/health visitor relationship as the mediating process for the 'service journey' upon which parents embark when pregnant or soon after the birth of their baby. It begins, usually, with an unsolicited, universal contact from the health visitor and ends when responsibility for the child is passed to school health services. Between those two points, the use of services varies in intensity and should, ideally, enable parents to confidently navigate their way through available provision, with appropriate support from a known and trusted health visitor. One mother in the service user study (Donetto et al, 2013), who had experienced a particularly difficult delivery, explained:

'The first time I met her she'd obviously heard about what had happened to me. I was kind of like the local discussion; wherever they work, everyone had heard.... 
So, she was lovely. She just came and introduced herself and said, 'Look, I'll check [baby] over and all that, but I really want to make sure that you're okay, because you're the one that has been through the ordeal, and I'm here for you.' She was just brilliant really .... I've only just stopped seeing her...' (Vicky, mother of one)

For parents, a good relationship is one in which they are really 'known' by the health visitor for their individual strengths and challenges and when the health visitors communicate recognition of these through the help offered. Support from a trusted health visitor, who knows the mother's story and can personalise the information, is central to enabling parental knowledge and developing confidence. Trials indicate that this parental confidence then translates into better service use (Wiggins et al 2005), including reduced attendance at emergency departments (Christie and Bunting 2011). The process of being given time and listened to in a non-judgemental way helps parents develop confidence and trust, so they can ask questions and seek information or reassurance when needed, for example:

'she [health visitor] tailored help to us as a family and I could be honest with her. If I said to her, 'Oh, I gave her a bottle last night', she wouldn't judge me, do you know what I mean? I'm not saying that the other health visitors would judge me but I wouldn't tell them if I had given a bottle of formula, I would be little bit more held back. So yes, I think it was just the fact that she was very much on the same wavelength as me in a way, she was just very easy to talk to.' (Scarlett, mother of three)

Health visitors cited the relationship they had with parents as a key source of satisfaction in their role, as they believed it helped them to 'make a difference' to the lives of children and families (Whittaker et al 2017). Bidmead (2013) identified practical aspects of service provision, such as having one health visitor over a period of time and receiving visits at home, as contributing to a successful relationship. Service users also 
identified the importance of being enabled to make use of local provision, such as community activities and children's centres, in fostering confidence and parental autonomy (Donetto and Maben 2015), particularly when services were well coordinated and they felt known and supported by their health visitor.

\section{Continuity and co-ordination}

Our literature search for evidence about different forms of skill mix and team working yielded very limited information, so our service user study focused particularly upon identifying which forms of service organisation parents found most helpful. At the outset, we noted that the terminology of 'health visiting team' is used in a variety of ways. Houston and Clifton (2001) trace 'team work' in health visiting back to the early 1990s, when the traditional model of 'one health visitor, one caseload' began to be challenged, with boundaries defined by geographical and/or GP alignment. Three key forms of team have developed since, which are sometimes combined in different ways:

1. Corporate caseload model, where a team of two or more health visitors share responsibility and accountability for a wider caseload of families (for examples, see Brocklehurst \& Adams, 2004; Houston \& Clifton, 2001)

2. Skill mix model, in which health visitors delegate specific activities to members of the team with lower-level qualifications (such as community nursery nurses, community staff nurses or health visitor assistants), whilst retaining overall accountability for their actions (concepts explored in depth by Carr and Pearson's (2005) qualitative study)

3. Collaborative model, where health visitors engage actively with local authority or third sector staff, possibly sharing premises and staff in joint activities, exemplified by the Scottish Starting Well demonstration project (Ross et al, 2005) where support staff working with NHS health visitors were employed by the local council. 
At times, this literature points to concerns about the potential fragmentation of services, but parents do not inevitably experience such problems, as indicated in this discussion from the service user study (Donetto et al 2013):

Juliet: You don't just see the one person. Where I go, I go to [name of centre], and there's a group of them. So I won't just see the one, I see quite a few.

Hillary: Yeah.

Juliet: And they're all like a team. So, I don't feel like I've got to say something to this person and I can't say it to this one or that one. I can just spill to the whole lot. I can sit there and have a brew with the lot of them and just spill. Because it's confidential and they're like your mates. You know you can turn to them about anything, which is nice. And they help you with anything you ask them. Anything. And they will help you with. (Juliet, mother of three, and Hillary, mother of two)

Parents expressed satisfaction with the service when they felt they were 'known' and health visitors acted as co-ordinators of different parts of service provision. That is, when the health visitor knew and understood an individual parent or family situation, meaning they could plan personalised service offers that accounted for their strengths and challenges, to ensure access to provision in the most straightforward way possible. This often involved more than just directing or signposting, as this mother explained:

'So, I went up there for [baby's] 12 week check and it was then that I broke down to [the health visitor] and told her exactly how lonely I was feeling because I didn't have any friends, because I'd only moved up here literally three weeks before he was born. [...] And that's when she helped me and put me in touch with the [Children's Centre] and got me a [family support worker], and helped me integrate a little bit better. [...] Because I went through a stage where I didn't want to go out of the house. [...] I was nervous to come down here on my own to the [baby class]. [...] [The family support worker] met me at my house and 
actually walked me down here [...] and she came in with me. [...]Without that I would never have got out and I wouldn't have got the friends that I've got now so...' (Denise, mother of one)

Later in the interview, that mother commented on the way that the health visitor, the family support workers, and other members of the team were working together. She also appreciated the health visitor assuming responsibility for coordination and staying in touch with her:

'[The family support workers] they're in contact with the health visitors; so they're working in liaison with each other which is really, really nice. And [my health visitor] did check-up that they were doing what they should be doing, so she was on the case very much.' (Denise, mother of one)

Collaboration with children's centre services was welcomed, where available, and team working appears acceptable to parents, as long as they experience some relational continuity with the health visitor and/or team member, and the provision is coordinated in a way that seems straightforward and easy to navigate as parents make their way on their particular 'service journey.' The enduring consequence of an effective relationship formed over earlier, repeated contact is that parents learn how the services operate and that, if new difficulties arise, they can initiate contact with a trusted professional and request help (Donetto and Maben 2015, Hanafin and Cowley, 2006; Pearson, 1991).

There is a lack of evaluative research about the different approaches to team working and skill mix, so we enquired about this, specifically, in the service users' study (Donetto et al 2013; Donetto and Maben 2015). The parents we spoke to wanted co-ordinated and coherent services, which increased their trust in services and their use of service provision. They wanted both home visiting and child health clinics, which each facilitate effective delivery of health visiting services and the Healthy Child Programme in 
different ways. Continuity is essential for health visitors to act as co-ordinators for different parts of service provision and for parents to feel 'known.' Knowing the individual family's strengths and difficulties means the health visitor is in a better position to personalise the service and help them to access services that capitalise on their strengths and minimise the challenges. Parents want someone who can help them navigate the system in this way, to make service use as straightforward as possible (Donetto et al 2013; Donetto and Maben 2015).

\section{Autonomy and flexibility}

Health visitors need the knowledge and ability to personalise service provision to demonstrate to parents that their situation is understood: in turn, this requires a set of skills and the autonomy to work flexibly according to a family's particular needs. This mother described the way one health visitor tuned in to her needs very rapidly, then arranged for her to have the necessary additional provision:

I should actually mention this, it actually was a health visitor who had come round, it was only about four days after we'd been home, [my daughter] had been discharged from the hospital, that came round actually to check my daughter's weight primarily and she looked at me and you know when someone says to you, 'Are you okay?' and the natural response as anyone who's busy is to go, 'Oh yeah, I'm fine.' [...] And I went, 'Oh yeah, I'm fine,' and she looked at me with that kind of look as, 'Are you really?' And it was her that made me realise that actually I wasn't. I feel quite emotional thinking about it now. [...] But it was actually her that made me realise that actually I wasn't really coping as well as I would have liked to be and that everything had really taken its toll on me. [...] And then, from that, I went to my GP and said, 'Look, I've been feeling this and thinking that and blah-blah-blah, ' and the GP referred me to [the counsellor].' (Heather, mother of three) 
This example shows the extent to which in-depth and complex health needs assessment are central to the work of the health visitor and getting it right for families. Such assessments are predicated on autonomous decision making based on high-level professional knowledge and judgement. Parents appreciate health visitors' ability to know and understand the family's situation, personalising service provision according to their needs and strengths. This helps parents to feel able to trust the health visitor, which is central to relationship-building, and can form a basis for parents to develop their own, autonomous decision making (Bidmead 2013, Donetto and Maben 2015). Health visitors aim to boost parents' confidence through reassurance and helping them get to know each other, in order to promote parental autonomy. This health visitor explained how they sought to promote child development and ensure that parents had access to services:

[HV3] The whole way of interacting, [.......], there is a lot of intensive contact up to a year but all the time I am working towards making sure the mother is becoming independent, autonomous and then you find that they move away so that relationship that friendliness is there but they see you less and less, moving away more and more...

From the perspective of health visitors, building both relationships and parental confidence worked best when services were organised to support them in flexibly using their professional skills in the way that seems right for the particular families. These two health visitors explained how, in a focus group for the 'start and stay' study (Whittaker et al 2017):

HV4 'Being able to address as many of their needs as they need addressing, without constraints being put on them ... like bureaucracy.' HV6 'For me, I could be doing a developmental check, and from that check I could see vulnerability, some targeted work that needs doing, carrying it forward, and it might go to the fourth level of universal services depending on my assessment 
and the needs'... (4-HV-grpB)

Universal provision offers a mechanism for identifying and targeting current needs and public health imperatives. Promoting preferred messages about, for example, breast feeding, smoking, vaccination and healthy eating all require a sensitivity and skill, particularly when working with parents whose views differ from official recommendations. Health visitors need to carefully balance the delivery of such public health information with a consideration of parental needs and wishes, which may give rise to tensions in practice. Coping with the ethical and practical tensions that arise from contradictory expectations was the subject of some earlier health visiting literature (Dingwall, 1982; Dingwall \& Robinson, 1990; Twinn, 1991), with more recent debates about 'disciplinary power' (Peckover 2002) and using health visitors as agents of state control (Greenway et al, 2008).

To deal with these tensions, health visitors need the ability and autonomy to shift their focus to from one family member to another within a contact, or to vary it according to emerging needs or interest from the parent (Cowley 1991). This, along with a determinedly non-judgemental stance, helps health visitors to better navigate any choppy waters between respecting privacy and individuality for each family, whilst also meeting the public health goals that underpin service specifications. Having the autonomy and flexibility to hone in on previously unidentified or hidden needs, perhaps whilst undertaking apparently routine activities, helps to jointly accommodate service users' perspectives and meet the public health expectations of service commissioners.

\section{Conclusion}

Pregnancy and the early weeks and years of life have been conclusively shown to be central to later health and well-being (Black et al 2017, Center on the Developing Child 2016). This period of early child development affects each child and family, and ultimately the whole community, as differences in individual life chances aggregate to 
create health inequalities across society (Marmot 2010). There is clear evidence that the return on investment in these early years far outweighs the benefits of later interventions (Heckman 2007). However, investments need to take account of what is known to work in improving outcomes in this early life stage.

Our programme of research revealed the key elements of a health visiting service that enables health gains for pregnant women, pre-school children and their families. These themes form the basis for inter-connected, recommended principles that should underpin the organisation of health visiting services. The first paper explained why and how universality needed to be the fundamental basis for all health visiting services (Cowley et al under review), with 'proportionate universalism' as a mechanism for reducing health inequalities. In this paper, we have explained the term 'the service journey,' which illustrates how parents can be enabled to understand provision and navigate their own way. Achieving this is closely linked to relationships, which are at the core of all health visiting provision, and services need to be organised in ways that enable them to be developed and maintained. Also, continuity and co-ordination are essential elements of team working, but there is little evidence to demonstrate the effectiveness, or not, of skill mix or staff substitution. Finally, professional autonomy is a necessary requirement, which enables health visitors to use their skills and knowledge of families to provide a flexible service, personalised to individual need. These skills and abilities, identified through our programme of research, are summarised in Box 3.

Place Box 3 near here

Health visitors are motivated by the opportunity to make a real difference to the lives of the families with whom they work (Whittaker et al 2017). They are employed to implement evidence-based programmes, such as the Healthy Child Programme (Department of Health 2009), which is underpinned by a raft of reviews (e.g., Barlow et al 2008, Axford et al 2015) and NICE guidance (see Box 2). The evidence summarised in Boxes 2 and 3, together with the aspects described in these two papers provide good evidence that health visitors can be effective at improving the mental and physical 
health of infants and their families. However, the extent to which this evidence is translated into successful provision depends on whether services are commissioned and organised in a way that enables health visitors to make best use of their knowledge, assessment ability and relational skills in applying research.

Body of text $=4196$ words, Abstract $=102$

\section{Acknowledgement}

This paper draws upon the Health Visitor Programme of Research ref: 0160058), which was commissioned and supported by the Department of Health in England as part of the work of the Policy Research Programme. The views expressed are those of the authors and not necessarily those of the Department of Health.

\section{Dedication}

These two papers are dedicated to Christine Bidmead, whose doctoral work on parenthealth visitor relationships was a key part of the literature review reported here, and who sadly died whilst these papers were being prepared. 


\section{Box 1: Programme of research: Summary of methods}

\section{Study 1: Scoping study and narrative review of the literature (Cowley et al 2013; 2015)}

Using a three-pronged search strategy, we screened over 3000 papers, seeking UK research that gave details of health visitors' practice. This elicited 348 papers through:

1. Broad initial search of HV literature (yielded 49 papers)

2. Structured and focused search (yielded 218 papers)

- 15 topics from HCP

- $\quad$ Search from 2004 - Feb 2012

- Limited to UK papers

3. Seminal/classic literature and papers deemed essential to study of health visiting; identified by experts who member-checked lists (yielded 81 papers)

Analysis informed by a framework derived from the Health Visitor Implementation Plan (Department of Health 2011).

Study 2: Health visiting: learning from the voice of service users (Donetto et al. 2013; Donetto and Maben 2015)

Aimed to learn from service users' experiences to inform the development of UK health visiting practice and services through:

1. Initial review of the academic literature about service users' experience of health visiting

2. A qualitative empirical study based on interview data gathered at two Early Implementer Sites in England

- 44 parents (42 mothers, 2 fathers) were interviewed

- Data were analysed using grounded theory methods.

Study 3: Start and Stay: Recruitment and retention of health visitors (Whittaker et al. 2013; 2017)

A qualitative study of factors impacting upon decisions to join or stay in the health visiting profession in two Early Implementer Sites

1. Data Collection from 53 participants: Students, Health Visitors, Managers, Lecturers, SHA leads

2. Used Appreciative Inquiry exercises during face-to-face and telephone interviews 


\begin{tabular}{|c|c|c|}
\hline Message & How this can be addressed & The work of the health visitor \\
\hline $\begin{array}{l}\text { The formation of sustainable } \\
\text { trusting relationships between } \\
\text { health providers and families } \\
\text { underpins effective service } \\
\text { delivery, intentional working } \\
\text { with families and better use of } \\
\text { health promotion messages } \\
\text { (Axford et al 2015). }\end{array}$ & $\begin{array}{l}\text { There should be continuity in } \\
\text { the service (Axford et al 2015) }\end{array}$ & $\begin{array}{l}\text { Health visitors should provide a } \\
\text { universal service for children } \\
\text { under five years (NICE, PH40) }\end{array}$ \\
\hline $\begin{array}{l}\text { Successful healthcare provision } \\
\text { varies in intensity over time and } \\
\text { responds to varying family } \\
\text { circumstances and needs over } \\
\text { time (Axford et al 2015). }\end{array}$ & $\begin{array}{l}\text { Health care providers must have } \\
\text { the opportunity for in depth } \\
\text { health needs assessment and } \\
\text { the opportunities, knowledge } \\
\text { and skills to identify and } \\
\text { respond when family } \\
\text { circumstances change (Axford et } \\
\text { al 2015). }\end{array}$ & $\begin{array}{l}\text { Promoting child social, } \\
\text { emotional and cognitive } \\
\text { wellbeing: recommends that } \\
\text { health visitors or midwives } \\
\text { should offer a series of intensive } \\
\text { home visits by an appropriately } \\
\text { trained nurse to parents } \\
\text { assessed to be in need of } \\
\text { additional support (NICE, PH40). }\end{array}$ \\
\hline $\begin{array}{l}\text { Many families, especially the } \\
\text { most vulnerable, may not be } \\
\text { aware of the extent of their own } \\
\text { or their children's health needs } \\
\text { or of the services which could } \\
\text { help them (Axford et al 2015). }\end{array}$ & $\begin{array}{l}\text { Health workers need to have } \\
\text { access to all families and to be } \\
\text { skilled in giving health } \\
\text { information in a way which is } \\
\text { meaningful and acceptable to } \\
\text { families (Axford et al 2015). }\end{array}$ & $\begin{array}{l}\text { Health workers should offer } \\
\text { outreach services to vulnerable } \\
\text { families to promote child social, } \\
\text { emotional and cognitive } \\
\text { wellbeing (NICE, PH40) }\end{array}$ \\
\hline $\begin{array}{l}\text { Making health changes is } \\
\text { difficult and often only partially } \\
\text { successful. Families need } \\
\text { workers who can help them } \\
\text { build resilience (Axford et al } \\
\text { 2015). }\end{array}$ & $\begin{array}{l}\text { Health workers need to work } \\
\text { within a system which builds } \\
\text { their resilience so that they can } \\
\text { support resilience in families. } \\
\text { Clinical supervision can help to } \\
\text { prevent 'burnout' in health } \\
\text { workers (Axford et al 2015). }\end{array}$ & $\begin{array}{l}\text { Models of clinical supervision } \\
\text { and safeguarding supervision } \\
\text { are well developed in health } \\
\text { visiting and the importance of } \\
\text { professional reflection and peer } \\
\text { review of caseload working is } \\
\text { well established. }\end{array}$ \\
\hline
\end{tabular}


Box 3: Messages identified in all three studies about what contributes to successful health visiting

i) Health visitors focus on health rather than illness (their work is salutogenic);

ii) In-depth and complex health needs assessment are central to the work of the health visitor. Complex health needs assessments are predicated on autonomous decision making based on a high level of professional knowledge and judgement;

iii) Relationship formation is at the core of effective health visiting and helps to facilitate health improvement and resilience;

iv) For families, a good relationship is one in which they are really 'known' by the health visitor for their individual strengths and challenges and when the health visitors recognise these in the help offered;

v) Families want co-ordinated and coherent services; coherent and co-ordinated services increase families' trust in services and their concordance with service provision;

vi) Home visiting and working in child health clinics facilitate delivery of health visiting services and the Healthy Child Programme; both are valued by parents

vii) Health visitors are motivated by the opportunity to make a real difference to the lives of the families with whom they work 


\section{References}

Appleton J V, Cowley S (2008a) Health visiting assessment processes under scrutiny: a case study of knowledge use during family health needs assessment: a case study. Int. J. Nurs. Stud. 45(5), 682-696

Appleton J V, Cowley S (2008b) Health visiting assessment - unpacking critical attributes in health visitor needs assessment practice: A case study. International Journal of Nursing Studies 45(2): 232-245.

Axford N, Barlow J, Coad J, Schrader-McMillan A, Bjornstad G, Berry V, Wrigley Z, Goodwin A, Ohlson C, Sonthalia S, Toft A, Whybra L, Wilkinson T (2015). Rapid Review to Update Evidence for the Healthy Child Programme 0-5. Public Health England, London.

Barlow, J., Schrader-Mc Millan, A., Kirkpatrick, S., Ghate, D., Smith, M., Barnes, J., (2008) Health-led Parenting Interventions in Pregnancy and Early Years. Department for Children, Schools and Families, London. DCSF-RW070.

Bedford, H. and Lansley, M. (2006) Information on childhood immunisation: parents' views. Community Practitioner, 79 (8) 252-255.

Bidmead, C. (2013). Health visitor/parent relationships: a qualitative analysis. Appendix 1. In: Cowley S, Whittaker K, Grigulis A, Malone M, Donetto, S, Wood H., Morrow E, Maben J (Eds.), Appendices for Why Health Visiting? A Review of the Literature about Key Health Visitor Interventions, Processes and Outcomes for Children and Families. National Nursing Research Unit, King's College London, London http://www.kcl.ac.uk/nursing/research/nnru/publications/index.aspx (accessed 23-072017) 
Black, M.P., Walker, S.P., Fernhold, L.C.H. et al. (2017) Early childhood development coming of age: science through the life course Lancet; 389: 77-90

Brocklehurst, N., and Adams, C. (2004). Embodying modernisation: Corporate working. Community Practitioner, 77(8), 292-296.

Brugha, T.S., Morrell, C., Slade, P. and Walters S. (2011). Universal prevention of depression in women postnatally: cluster randomized trial evidence in primary care. Psychological Medicine, 41(4), 739-748

Bryans, A. (2005) At home with clients: a study of health visiting expertise. Community Practitioner, 78 (10) 358-362.

Carr, S.M., Pearson, P.H. (2005). Delegation: Perception and practice in community nursing. Primary Health Care Research and Development, 6(1), 72-81.

Christie, J. and Bunting, B. (2011) The effect of health visitors' postpartum home visit frequency on first-time mothers: Cluster randomised trial. International Journal of Nursing Studies, 48 (6) 689-702.

Council for the Education and Training of Health Visitors (CETHV) (1977) An Investigation into the Principles and Practice of Health Visiting, London, CETHV

Cowley, S., Whittaker, K., Grigulis, A., Malone, M., Donetto, S., Wood, H., Morrow, E., Maben, J. (2013) Why Health Visiting? A Review of the Literature about Key Health Visitor Interventions, Processes and Outcomes for Children and Families. National Nursing Research Unit, King's College London, London http://www.kcl.ac.uk/nursing/research/nnru/publications/index.aspx (accessed 23-072017)Cowley S. Whittaker, K. Malone, M. Donetto, S. Grigulis, A. Maben J. (2015) Why 
health visiting? Examining the potential public health benefits for health visiting practice within the universal service: a narrative review of the literature. International Journal of Nursing Studies. 52(1):465-80, doi: 10.1016/j.ijnurstu.2014.07.013

Davis, H., Day, C. (2010). Working in Partnership: The Family Partnership Model: Pearson Education Ltd, London.

Davis, H., Dusoir, T., Papadopoulou K, et al (2005). Child and Family Outcomes of the European Early Promotion Project. International Journal of Mental Health Promotion, 7, 63-81.

Day, C., Morton, A., Ibbeson, A., Maddison, S., Pease, R., \& Smith, K. (2014).

Antenatal/Postnatal promotional guide: Evidence-based intervention. Journal of Health Visiting, 2(12), 658-669.

Department of Health Social Services and Public Safety (2010) Healthy Child Healthy Future. A framework for the universal child health promotion programme in Northern Ireland. Pregnancy to 19 years. Belfast, DHSSPSNI. Available at: www.dhsspsni.gov.uk Department of Health, (2011). Health Visitor Implementation Plan 2011-2015: A Call to Action. Department of Health, London.

Department of Health and Department for Children, Schools and Families, (2009). The Healthy Child Programme: Pregnancy and the First Five Years of Life. Department of Health, London.

Dingwall, R. (1982) Community nursing and civil liberty, Journal of Advanced Nursing, 7, 337-46.

Dingwall, R., Robinson, K. (1990) Policing the family? Health Visiting and the public surveillance of private behaviour. In Gubrium, J. and Sankar, A. (eds) The Home Care Experience: Ethnography and Policy. Newbury Park, CA: Sage. 
Donetto, S., Malone, M., Hughes, J., Morrow, E., Cowley, S. \& Maben. J. (2013) Health

visiting: the voice of service users - Learning from service users' experiences to inform the development of UK health visiting practice and services. London: National Nursing Research Unit, King's College London http://www.kcl.ac.uk/nursing/research/nnru/publications/index.aspx (accessed 23-072017)

Donetto, S. and Maben, J. (2015) 'These places are like a godsend': a qualitative analysis of parents' experiences of health visiting outside the home and of children's centres services. Health Expectations 18(6):2559-69.

Greenway, J., Dieppe, P., Entwistle, V., and Meulen, R. (2008). 'Facing the future': the government's real agenda for health visitors. Community Practitioner, 81(11), 29-32. Hanafin S, Cowley S (2006). Quality in preventive and health-promoting services: constructing an understanding through process. Journal of Nursing Management, 14(6), 472-482.

Heckman, J.J. (2007) The Economics, Technology and Neuroscience of Human Capability Formation. Proceedings of the National Academy of Sciences. 104(3), 13250-13255.

Houston, A.M. \& Clifton, J, (2001). Corporate working in health visiting: a concept analysis. Journal of Advanced Nursing, 34(3), 356-366.

Marmot, M., Allen, J., Goldblatt, P., Boyce, T., McNeish, D., Grady, M., et al. (2010) Fair society, healthy lives: The Marmot Review - Strategic review of health inequalities in England post-2010. The Marmot Review, http://www.instituteofhealthequity.org/resources-reports/fair-society-healthy-livesthe-marmot-review (accessed 23-07-17) 
Morrell, C.J., Slade, P., Warner, R., Paley, G., Dixon, S., Walters, S. J. et al. (2009). Clinical effectiveness of health visitor training in psychologically informed approaches for depression in postnatal women: pragmatic cluster randomised trial in primary care. BMJ: British Medical Journal, 338, (7689) 1-14.

National Institute for Health and Care Excellence (NICE) (2012) Social and emotional well-being: early years (Public Health Guideline, PH40) London, NICE

Pearson, P. (1991). Clients' perceptions: the use of case studies in developing theory 4. Journal of Advanced Nursing, 16(5), 521-528.

Peckover, S. (2002b) Supporting and policing mothers: an analysis of the disciplinary practices of health visiting. Journal of Advanced Nursing, 38(4), 269-377.

Puura, K., Davis, H., Mäntymaa, M., et al. (2005). The Outcome of the European Early Promotion Project: Mother-Child Interaction. International Journal of Mental Health Promotion, 7(1), 82-94.

Ross, M. K., Caestecker, L., Sinclair, M., \& Lakey, T. (2005). The Starting Well health demonstration project. The Journal of Primary Prevention, 26(3), 205-220.

Center on the Developing Child at Harvard University (2016). Building Core Capabilities for Life: The Science Behind the Skills Adults Need to Succeed in Parenting and in the Workplace. http://www.developingchild.harvard.edu Accessed 27/03/18

The Scottish Government (2015) Universal Health Visiting Pathway in Scotland. Pre-birth to pre-school. Edinburgh, The Scottish Government. Available at:

http://www.gov.scot/Publications/2015/10/9697 Accessed: 6/11/17 
Twinn, S. (1991) Conflicting paradigms of health visiting: a continuing debate for professional practice. Journal of Advanced Nursing 16, 966 - 973.

Welsh Government (2016) Healthy Child Wales Programme: Quality Assurance Framework. Cardiff, Welsh Government. Available at:

http://fis.ceredigion.gov.uk/healthy-child-wales-programme-hcwp/

Whittaker, K. A., Malone, M., Cowley, S., Grigulis, A., Nicholson, C., and Maben, J. (2017), Making a difference for children and families: an appreciative inquiry of health visitor values and why they start and stay in post. Health Soc Care Community, 25: 338348.

Wiggins, M., Oakley, A., Roberts, I., Turner, H., Rajan, L., Austerberry, H., et al. (2005). Postnatal support for mothers living in disadvantaged inner city areas: a randomised controlled trial. Journal of Epidemiology and Community Health, 59(4), 288-295. 